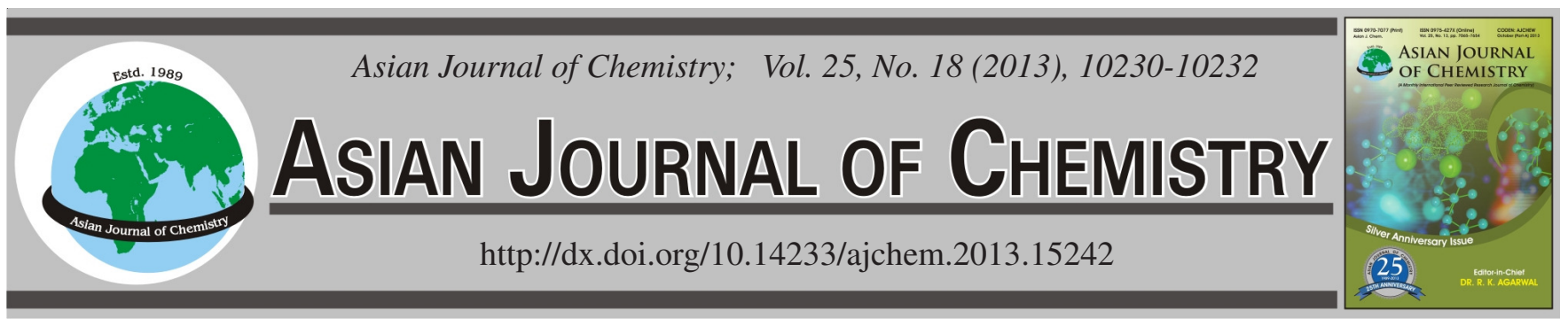

\title{
Morphologies of Nanostuctured ZnO Prepared by Matrix-Assisted Method and its Effects on Photocatalytic Activity
}

\author{
S.N.M. Nordin ${ }^{1}$, A.H. Abdullah ${ }^{2, *}$ and Z. ZainAL ${ }^{2}$
}

${ }^{1}$ Institute of Advanced Technology, Universiti Putra Malaysia, 43400 UPM Serdang, Selangor, Malaysia

${ }^{2}$ Department of Chemistry, Faculty of Science, Universiti Putra Malaysia, 43400 UPM Serdang, Selangor, Malaysia

*Corresponding author: Fax: +60 3 89435380, Tel: +60 38946 6777; E-mail: halim@upm.edu.my

\begin{abstract}
Zinc oxide nanoparticles have been successfully synthesized by matrix-assisted method using activated carbon as a matrix and zinc nitrate and zinc acetate as $\mathrm{ZnO}$ precursors. Different weight percentages (10-40 wt \%) of $\mathrm{Zn}$ precursor were loaded onto activated carbon and calcined in air at 500 and $600{ }^{\circ} \mathrm{C}$, producing highly crystallined $\mathrm{ZnO}$ particles with a wurtzite structure. Nanospherical $\mathrm{ZnO}$ and a mixture of nanosphere and nanorod $\mathrm{ZnO}$ were produced from zinc nitrate and zinc acetate, respectively. The efficiency study of the synthesized $\mathrm{ZnO}$ in the photodegradation of rhodamine $6 \mathrm{G}$ indicated that $\mathrm{ZnO}$ produced from zinc acetate is more effective than that from zinc nitrate, possibly due to the differences in the morphology of the synthesized $\mathrm{ZnO}$.
\end{abstract}

Key Words: Zinc oxide, Activated carbon, Photodegradation, Dyes.

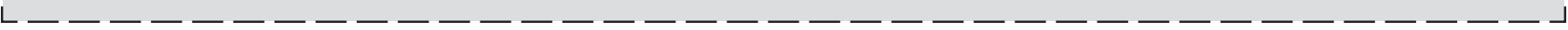

\section{INTRODUCTION}

Nanostructured materials, such as metal oxides, are being rapidly developed due to their efficacy and cost in environmental remediation, as they offer high specific surface areas and a high surface area to volume ratio ${ }^{1}$. The zinc oxide $(\mathrm{ZnO})$ nanostructure is one of the most important semiconductors with a wide-band gap $(\Delta \mathrm{E} \approx 3.37 \mathrm{eV}$ at $300 \mathrm{~K})$ that has large excitation binding energy ( $60 \mathrm{meV}$ at room temperature $)^{2}$. Zinc oxide has been studied for applications in gas sensing ${ }^{3}$, electronics ${ }^{4}$, hybrid solar cells ${ }^{5}$, food packaging ${ }^{6}$ and also in water and gas treatments ${ }^{7,8}$. There are various techniques to produce nano-sized zinc oxide; hydrothermal ${ }^{9}$, modified wet chemicals ${ }^{3,10}$ and homogeneous precipitation ${ }^{11}$. Depending on the synthesis, zinc oxides of various sizes, morphologies and properties can be produced. The reported $\mathrm{ZnO}$ nanostructures include multipod, flower-like, shuttle-like ${ }^{12}$, nanoneedles, nanorods ${ }^{2}$, nanowires ${ }^{13,14}$ and nanopencils ${ }^{15}$.

Schwickardi et al. ${ }^{16}$ developed and suggested a novel method for preparation of a high surface area metal oxide by using the matrix-assisted method. They reported that high surface area metal oxides such as magnesium oxide and titanium dioxide can be produced by using activated carbon as the supporting material.

In this study, $\mathrm{ZnO}$ nanostructures were synthesized by matrix-assisted method using activated carbon as a matrix. The effects of zinc precursor, zinc loading and calcination temperatures on the properties of $\mathrm{ZnO}$ were investigated. The photocatalytic activity of $\mathrm{ZnO}$ in the degradation of Rhodamine $6 \mathrm{G}$ was also examined.

\section{EXPERIMENTAL}

Zinc oxide $(\mathrm{ZnO})$ was prepared by using matrix-assisted method $^{17,18}$. Activated carbon (AC) from coconut shells (Kekwa Indah Sdn. Bhd) was used as the matrix, while zinc acetate (Merck) and zinc nitrate (Hamburg) were used as $\mathrm{ZnO}$ precursors. $\mathrm{ZnO}$ produced by using zinc acetate and zinc nitrate was labeled as ZA and ZN, respectively.

The activated carbon was initially treated with $\mathrm{HCl}(1 \mathrm{~g}$ activated carbon: $2.5 \mathrm{~mL} \mathrm{HCl}$ ) for $0.5 \mathrm{~h}$ to eliminate impurities. The activated carbon was then washed with deionised water and oven-dried. In order to produce $\mathrm{ZnO}$, the activated carbon was impregnated with a calculated amount of zinc salt solution to produce $10-40 \%$ wt of $\mathrm{Zn}$. The mixture was stirred for $4 \mathrm{~h}$, sonicated for $0.5 \mathrm{~h}$ and oven-dried. The dried mixture was calcined in air at 500 and $600{ }^{\circ} \mathrm{C}$ for $6 \mathrm{~h}$ to remove the activated carbon. The product, $\mathrm{ZnO}$, was characterized by X-ray diffraction, scanning electron microscope and transmission electron microscope.

The photocatalytic activity of $\mathrm{ZnO}$ was evaluated by degradation of Rhodamine 6G (R6G) dye. $0.2 \mathrm{~g}$ of $\mathrm{ZnO}$ was added to a solution of $10 \mathrm{ppm}$ Rhodamine $6 \mathrm{G}$ in a photoreactor. The mixture was magnetically stirred and was allowed to equilibrate in darkness for $1 \mathrm{~h}$ before being irradiated with a UVA lamp 
for $4 \mathrm{~h}$. After predetermined time intervals, test samples were drawn and filtered to remove any trace of $\mathrm{ZnO}$ nanoparticles. The concentration of the dye in the test sample was determined by UV-visible spectrometer.

\section{RESULTS AND DISCUSSION}

Characteristics of $\mathbf{Z n O}$ : In order to investigate the effect of the zinc precursor, the activated carbon was impregnated with 25 wt $\%$ zinc solution followed by calcinations at 500 and $600{ }^{\circ} \mathrm{C}$. The $\mathrm{ZnO}$ produced using nitrate and zinc acetate solutions were labeled as 25ZNT and 25ZAT, respectively, where $\mathrm{T}$ represents the calcination temperatures.

The XRD patterns of 25ZN500 and 25ZA500 (Fig. 1) show sharp and narrow peaks with strong intensity that matches the hexagonal wurtzite crystal structure of $\mathrm{ZnO}$ (JCPDS card No. 65-3411). The XRD peaks of 25ZN500 are much more intense than those characteristic of 25ZA500. Additionally, samples calcined at $600{ }^{\circ} \mathrm{C}$ (25ZN600 and 25ZA600) also showed sharper and more intense XRD peaks than those of samples calcined at $500{ }^{\circ} \mathrm{C}$, indicating that samples produced using zinc nitrate have higher crystallinity and that the crystallinity increases with calcination temperature. In contrast to the reported XRD patterns which showed the presence of alumina and silica ${ }^{8,17,18}$, no peaks due to impurities were observed, which indicates that the type and quality of activated carbon and the acid treatment are important in order to produce pure $\mathrm{ZnO}$.
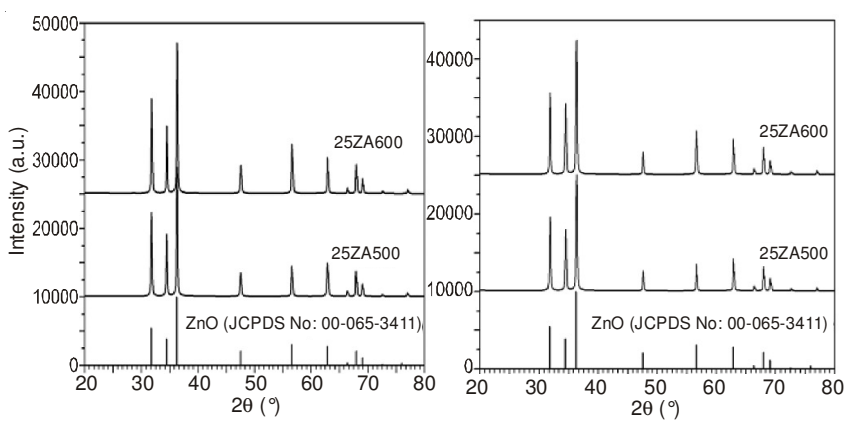

Fig. 1. XRD patterns of $\mathrm{ZnO}$ synthesized from zinc acetate (25ZA) and zinc nitrate $(25 \mathrm{ZN})$ at different calcination temperatures

Fig. 2 shows the FESEM images of $\mathrm{ZnO}$, which are spherical for 25ZN500 and a mixture of spheres and rods for 25ZA500. The results suggest that the morphology of the synthesized $\mathrm{ZnO}$ may be influenced by the zinc precursor.
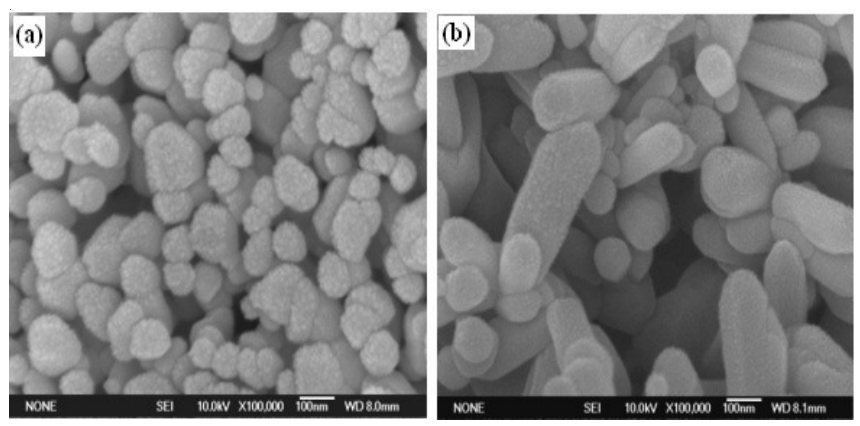

Fig. 2. FESEM images of (a) 25ZN500 and (b) 25ZA500

The TEM images of samples calcined at 500 and $600{ }^{\circ} \mathrm{C}$ are shown in Fig. 3. Although the morphology of the $\mathrm{ZN}$
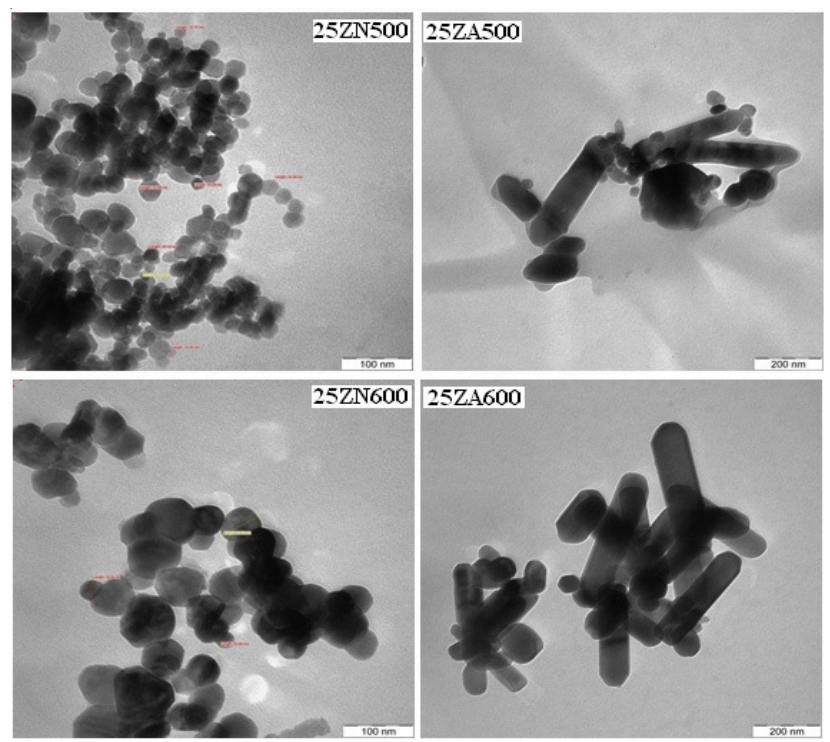

Fig. 3. TEM images of $\mathrm{ZnO}$ samples calcined at 500 and $600{ }^{\circ} \mathrm{C}$ using zinc nitrate $(\mathrm{ZN})$ and zinc acetate $(\mathrm{ZA})$ as precursors

sample remained spherical, the $\mathrm{ZnO}$ particle size increased from $10-50 \mathrm{~nm}$ to $20-100 \mathrm{~nm}$ when the calcination temperature increased to $600{ }^{\circ} \mathrm{C}$. This can be attributed to aggregation as the calcination temperature increased. For 25ZA500, spherical $\mathrm{ZnO}$ was $20-70 \mathrm{~nm}$ while the dimensions of the $\mathrm{ZnO}$ rods were $40-100 \mathrm{~nm}$ in diameter and 90-270 $\mathrm{nm}$ long. Upon calcination at $600{ }^{\circ} \mathrm{C}$, rods were more numerous and larger with dimensions of 50-130 $\mathrm{nm}$ in diameter and 200-400 nm in length. The growth of the nanorods was attributed to the decomposition of the acetate during calcination followed by repetitive $\mathrm{ZnO}$ reduction and $\mathrm{Zn}$ oxidation ${ }^{18}$.

The effect of $\mathrm{Zn}$ precursor loading (10-40 wt \%) on the properties of synthesized $\mathrm{ZnO}$ was also investigated. Although the morphology of ZN samples remains unchanged (Fig. 4), the size of the $\mathrm{ZnO}$ nanosphere increased with the weight percentage, which is from $0-60 \mathrm{~nm}$ at $10 \mathrm{wt} \%$ to $0-90 \mathrm{~nm}$ at $40 \mathrm{wt} \%$. This indicates that the amount of $\mathrm{Zn}$ precursor increases the number of $\mathrm{ZnO}$ particles formed. These particles then formed agglomerates, resulting in bigger particles.

Different morphologies were observed at different $\mathrm{Zn}$ precursor loadings in the ZA samples (Fig. 4). At a low loading (10 wt \%, 10ZA500), only agglomerated $\mathrm{ZnO}$ nanospheres were formed. When the loading was increased (25 wt \%, 25ZA500), a mixture of rod and spherical $\mathrm{ZnO}$ was observed. The rod shaped $\mathrm{ZnO}$ became dominant and grew longer when Zn precursor was increased to $40 \mathrm{wt} \%$ (40ZA500). This morphological change is attributed to the growth of $\mathrm{ZnO}$ on the agglomerated $\mathrm{ZnO}^{18}$.

Photodegradation studies: The photocatalytic performance of the synthesized $\mathrm{ZnO}$ was evaluated by the degradation of Rhodamine 6G (R6G). Fig. 5 shows that the percentage degradation of Rhodamine $6 \mathrm{G}$ generally increases in proportion with the amount of zinc loaded on the activated carbon and decreases with increasing calcination temperature.

Comparing the performance of the ZN 500 series, the highest percentage degradation of Rhodamine $6 \mathrm{G}$ was observed for 40ZN500, which has the biggest particle size and highest crystallinity. This indicates that particle size and crystallinity of 


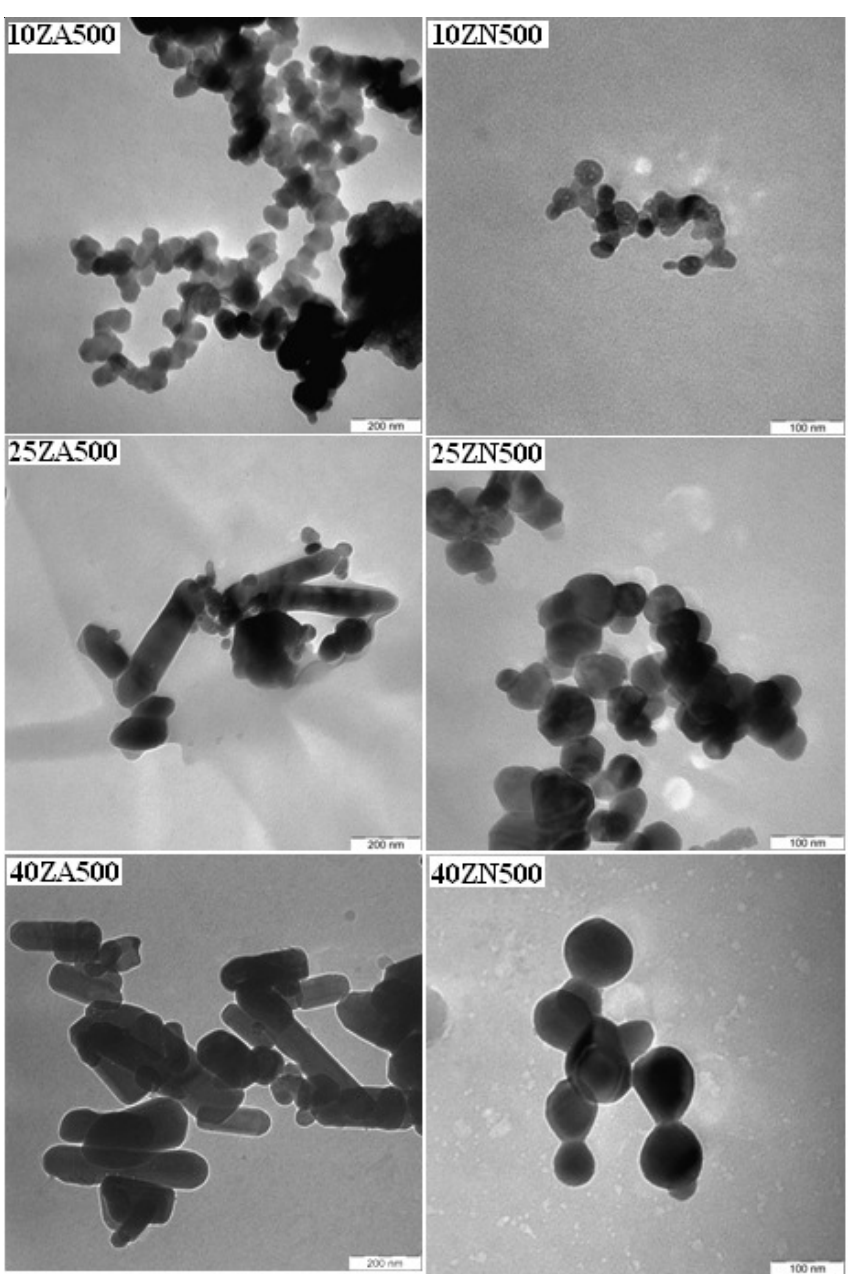

Fig. 4. TEM images of $\mathrm{ZnO}$ samples prepared at different $\mathrm{Zn}$ precursor loads calcined at $500{ }^{\circ} \mathrm{C}$ with zinc nitrate $(\mathrm{ZN})$ and zinc acetate (ZA) as precursors

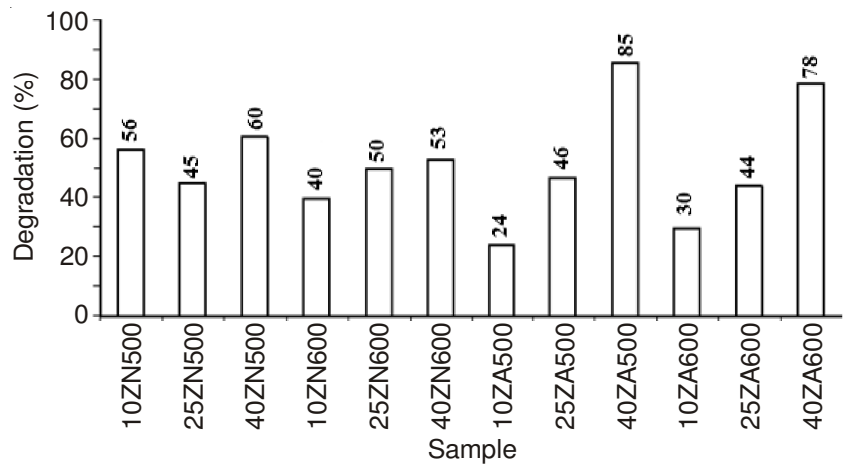

Fig. 5. Photodegradation of Rhodamine $6 \mathrm{G}$ by synthesized $\mathrm{ZnO}$ under UVA irradiation (Condition: $0.2 \mathrm{~g}$ of $\mathrm{ZnO}, 10 \mathrm{ppm}$ of Rhodamine 6G)

the $\mathrm{ZnO}$ play significant roles in Rhodamine $6 \mathrm{G}$ degradation. Although 10ZN500 particles are smaller than 25ZN500, its efficiency in the degradation of Rhodamine $6 \mathrm{G}$ is higher, possibly due to agglomeration of these particles in the dye solution, making it suitable for the degradation of the dye. This can be inferred as the percentage degradation of the dye by $10 Z$ Z 500 is similar to that of 40ZN500.

For the ZA500 series, the increase in percentage degradation of Rhodamine $6 \mathrm{G}$ can be attributed to the morphology of the produced $\mathrm{ZnO}$. The rod-shaped $\mathrm{ZnO}$, the dominant shape observed for 40ZA500, is more efficient than spherical $\mathrm{ZnO}$ in the degradation of Rhodamine $6 \mathrm{G}$, as observed in 10ZA500 and the $\mathrm{ZN}$ series.

The percentage degradation of the $\mathrm{R} 6 \mathrm{G}$ by $\mathrm{ZnO}$ calcined at $600{ }^{\circ} \mathrm{C}$ for both the $\mathrm{ZN}$ and $\mathrm{ZA}$ series was found to be slightly lower than that of $\mathrm{ZnO}$ calcined at $500{ }^{\circ} \mathrm{C}$. It is a well known fact that the size of particles increase with the calcination temperature due to sintering, which leads to a reduction in surface area, which in turn affects the generation of the hydroxyl radical and subsequently the degradation of Rhodamine 6G.

\section{Conclusion}

In this study, various $\mathrm{ZnO}$ nanostructures were successfully produced by a matrix-assisted method. The morphology of the $\mathrm{ZnO}$ produced is dependent on the zinc precursor and the amount of zinc precursor loaded onto the activated carbon. When zinc nitrate was used as precursor, only spherical $\mathrm{ZnO}$ was produced. However, when zinc acetate was used as precursor, the morphology changes from spherical to rods as the percentage of zinc acetate loaded into the activated carbon is increased. The results show that the performance of the synthesized $\mathrm{ZnO}$ in degrading Rhodamine $6 \mathrm{G}$ in an aqueous solution is significantly influenced by the morphology of $\mathrm{ZnO}$.

\section{ACKNOWLEDGEMENTS}

The authors acknowledged the financial assistance from Universiti Putra of Malaysia of a graduate fellowship to S.N.M. Nordin.

\section{REFERENCES}

1. G.E. Fryxell and S.V. Mattigod, In ed.: C.S.S.R. Kumar, in Nanomaterials: Toxicity, Health and Environmental Issue, Wiley-VCH Verlag $\mathrm{GmbH}$ \& Co., Weinheim, pp. 189-205 (2006).

2. L. Wang, X. Zhang, C. Shao, X. Hong, Q. Qiao and Y. Liu, Mater. Chem. Phys., 15, 547 (2009).

3. M.K. Hossain, S.C. Ghosh, Y. Boontongkong, C. Thanachayanont and J. Dutta, J. Metastable Nanocryst. Mater., 23, 27 (2005).

4. C. Casteleiro, H. L. Gomes, P. Stallinga, L. Bentes, R. Ayouchi and R. Schwarz, J. Non-Cryst. Solids, 354, 2519 (2008).

5. S.I. Na, S.S. Kim, W.K. Hong, J.W. Park, J. Jo, Y.C. Nah, T. Lee and D.Y. Kim, Electrochim. Acta, 53, 2560 (2008).

6. Q. Chaudhry, M. Scotter, J. Blackburn, B. Ross, A. Boxall, L. Castle, R. Aitken and R. Watkins, Food Addit. Contam. A-Chem., 25, 241 (2008).

7. N. Daneshvar, S. Aber, M. Seyeddorraji, A. Khataee and M. Rasoulifard, Sep. Purif. Technol., 58, 91 (2007).

8. Y.J. Lee, N.-K. Park, G.B. Han, S.O. Ryu, T.J. Lee and C.H. Chang, Curr. Appl. Phys., 8, 746 (2008).

9. L.N. Dem'yanets, L.E. Li and T.G. Uvarova, J. Mater. Sci., 41, 1439 (2006).

10. A. Gupta, H.S. Bhatti, D. Kumar, N.K. Verma and R.P. Tandon, Dig. J. Nanomater. Biostruct., 1, 1 (2006).

11. Y. Liu, Z. Jian-er, A. Larbot and M. Persin, J. Mater. Process. Technol., 189, 379 (2007).

12. J. Wang, J. Cao, B. Fang, P. Lu, S. Deng and H. Wang, Mater. Lett., 59 , 1405 (2005).

13. J. Zhang, M.K. Li, L.Y. Yu, L.L. Liu, H. Zhang and Z. Yang, Appl. Phys. A-Mater. Sci. Process., 97, 869 (2009).

14. H. Zhou and Z. Li, Mater. Chem. Phys., 89, 326 (2005).

15. R.C. Wang, C.P. Liu, J.L. Huang, S.J. Chen, Y.K. Tseng and S.C. Kung, Appl. Phys. Lett., 87, 1 (2005).

16. M. Schwickardi, T. Johann, W. Schmidt, O. Busch and F. Schüth, Stud. Surf. Sci. Catal., 143, 93 (2000).

17. N.K. Park, J.D. Lee, T.J. Lee, S.O. Ryu and C.H. Chang, Fuel, 84, 2165 (2005).

18. N.K. Park, Y.J. Lee, G.B. Han, S.O. Ryu, T.J. Lee, C.H. Chang and G.Y. Han, Colloids Surf. A, 313-314, 66 (2008). 